\title{
Seleksi 16 Galur Harapan Cabai Rawit (Capsicum annuum L.) untuk Toleransi terhadap Salinitas
}

\section{Selection of 16 Elite Lines of Chili Pepper (Capsicum annuum L.) for Salinity Tolerance}

\author{
Musadia Afa $^{1}$, Marlina Mustafa ${ }^{1 *}$, Yolanda Fitria Syahri ${ }^{1}$, Juniaty Arruan Bulawan ${ }^{1}$, dan Musdalifa ${ }^{2}$ \\ ${ }^{1}$ Program Studi Agroteknologi, Fakultas Pertanian, Perikanan dan Peternakan \\ Universitas Sembilanbelas November Kolaka \\ Jl. Pemuda No. 339, Tahoa, Kabupaten Kolaka, Sulawesi Tenggara 93517, Indonesia \\ ${ }^{2}$ Mahasiswa Program Studi Agroteknologi, Fakultas Pertanian, Perikanan dan Peternakan \\ Universitas Sembilanbelas November Kolaka \\ Jl. Pemuda No. 339, Tahoa, Kabupaten Kolaka, Sulawesi Tenggara 93517, Indonesia
}

Diterima 17 Juni 2021/Disetujui 16 Agustus 2021

\begin{abstract}
The utilization of saline soil for chili pepper production might be established by selecting tolerant varieties so that the growth and production remain stable even though they are planted on marginal lands. The purpose of this study was to determine the selection criteria for tolerant chili pepper to salinity and select a chili pepper genotype that are tolerant to salinity based on morphological characters and yield components. This study was carried out in Kolaka Regency, Southeast Sulawesi, from November 2020 to May 2021. The study was carried out on saline land nearby the coast with an average of electrical conductivity (EC) of $6.66 \mathrm{dS} \mathrm{m} \mathrm{m}^{-1}$. The study used a randomized complete block design with 22 lines of elite chili pepper and three replications. The results showed that characters as selection criteria for salinity tolerant were plant height, days to flowering, days to harvest, and fruit length because they had a significant effect on fruit weight per plant and high broad-sense heritability of $81.53 \%, 94.75 \%, 95.05 \%$, and $87.45 \%$, respectively. Based on these characters, the genotype selected as a candidate for the tolerant variety was G17. This genotype can be recommended for the development of chili pepper in saline soil.
\end{abstract}

Keywords: heritability, saline land, tolerance, yield

\section{ABSTRAK}

Pemanfaatan lahan salin untuk pengembangan cabai rawit dapat dilakukan dengan menyeleksi varietas yang toleran sehingga pertumbuhan dan produksinya tetap baik meskipun ditanam pada lahan tercekam. Penelitian ini bertujuan untuk menentukan kriteria seleksi toleran cabai rawit terhadap salinitas dan menyeleksi galur harapan cabai rawit yang toleran berdasarkan karakter morfologi dan komponen produksi. Penelitian ini dilaksanakan di Kabupaten Kolaka, Sulawesi Tenggara dari November 2020 hingga Mei 2021. Penelitian dilaksanakan pada lahan salin dekat pantai dengan rata-rata hasil analisis daya hantar listrik (DHL) $6.66 \mathrm{dS} \mathrm{m}^{-1}$. Penelitian menggunakan rancangan kelompok lengkap teracak dengan 22 galur elit cabai rawit yang diulang sebanyak tiga kali. Hasil penelitian menunjukkan bahwa karakter yang potensial untuk dijadikan kriteria seleksi toleran salinitas pada cabai rawit adalah tinggi tanaman, umur berbunga, umur panen, dan panjang buah karena menunjukkan pengaruh yang nyata terhadap bobot buah per tanaman dan memiliki nilai heritabilitas arti luas yang tinggi, masing-masing $81.53 \%, 94.75 \%, 95.05 \%, 87.45 \%$. Berdasarkan karakter tersebut, galur yang terpilih sebagai calon varietas toleran adalah G17. Galur ini dapat direkomendasikan untuk pengembangan cabai rawit di lahan salin.

Kata kunci: heritabilitas, korelasi, kriteria seleksi, lahan salin, produksi

\footnotetext{
* Penulis untuk korespondensi. e-mail: linamarlinamus@gmail.com
} 


\section{PENDAHULUAN}

Cabai rawit (Capsicum annuum L.) termasuk salah satu komoditas strategis karena tidak hanya diperuntukkan bagi kebutuhan industri, tetapi juga dibutuhkan oleh rumah tangga. Tanaman cabai rawit sangat sensitif terhadap perubahan cuaca yang berakibat pada fluktuasi pasokan dan harga sehingga sangat berpengaruh terhadap inflasi, dengan memberikan andil tertinggi untuk komoditas sebesar 0.04\% (Fauzia, 2021). Salah satu penyebab terjadinya fluktuasi produksi cabai karena sebaran produksi terkonsentrasi pada wilayah atau pulau tertentu, sementara konsumen cabai tersebar merata di seluruh wilayah.

Produksi cabai rawit mengalami peningkatan dari tahun 2019 sebanyak 1.37 juta ton menjadi 1.46 juta ton pada tahun 2020 dengan tingkat produktivitas 7.8 ton ha ${ }^{-1}$ (Yuniartha dan Hidayat, 2021). Akan tetapi masih rendah dibandingkan dengan produktivitas cabai pada tahun 1995 yang mencapai 8.73 ton $\mathrm{ha}^{-1}$. Luas panen cabai untuk periode 2014-2018 cenderung meningkat dengan rata-rata pertumbuhan luas panen di Jawa sebesar $6.17 \%$ sedangkan di Luar Jawa sebesar 5.70\%. Peningkatan luas panen tersebut belum mampu mengimbangi perkembangan konsumsi cabai, yang mengalami peningkatan hingga 57.14\% (2018) dari tahun sebelumnya (Pusdatin, 2020; Yunandra et al., 2017). Pertambahan luas panen dan perbaikan potensi produksi masih perlu dilakukan untuk mengatasi kekurangan pasokan cabai.

Perluasan penanaman cabai pada lahan subur terbatas akibat meningkatnya alih fungsi lahan, sehingga perlu diarahkan ke lahan marginal yaitu lahan salin yang mengalami peningkatan luas setiap tahun. Luas lahan salin di Indonesia diperkiran mencapai 440,300 ha (Narwiyan et al., 2016) dan terus mengalami peningkatan setiap tahunnya (Sukarman et al., 2018). Menurut Qadir (2016) luas lahan salin di dunia mencapai 20\% luas daratan.

Salinitas merupakan faktor lingkungan yang berpengaruh terhadap penurunan produktivitas tanaman (Qadir, 2016; Balasankar et al., 2017). Kadar garam yang tinggimenyebabkan terhambatnya penyerapan air, keracunan ion dan ketidakseimbangan nutrisi pada tanaman (Ifediora et al. 2014). Akan tetapi besarnya pengaruh salinitas berbeda berdasarkan jenis dan kadar salinitasnya serta varietas tanaman (Niu et al., 2010; Nizam et al., 2017).

Metode yang digunakan untuk mengurangi kadar garam dalam tanah adalah melalui pencucian garam yang terakumulasi dalam profil tanah dan perlakuan teknik budidaya dengan input yang tinggi. Teknik budidaya membutuhkan biaya yang cukup tinggi dan pengaruhnya tidak berkelanjutan sehingga harus dilakukan setiap musim tanam. Perakitan varietas toleran salinitas merupakan salah satu solusi yang efektif untuk meningkatkan adaptasi tanaman cabai di lahan salin.

Informasi genotipe toleran, kriteria seleksi, aksi gen toleransi dan penentuan metode seleksi yang tepat diperlukan untuk membantu pemulia merakit varietas cabai toleran salinitas secara efisien. Seleksi memiliki peran yang sangat penting terhadap keberhasilan kegiatan pemuliaan tanaman. Galur elit adalah galur yang telah melewati seleksi hingga generasi lanjut pada kondisi lingkungan yang optimal. Seleksi terhadap galur harapan akan lebih efektif mempersingkat proses seleksi. Penelitian ini bertujuan untuk menentukan kriteria seleksi toleran cabai rawit terhadap salinitas dan menyeleksi 16 galur harapan cabai rawit yang toleran berdasarkan karakter morfologi dan komponen produksi sehingga dapat merekomendasikan galur harapan toleran yang akan berproduksi dengan baik meskipun dikembangkan pada lahan salin.

\section{BAHAN DAN METODE}

Penelitian dilaksanakan di lahan pesisir pantai di Desa Tanggetada, Kabupaten Kolaka, Sulawesi Tenggara, pada bulan November hingga Mei 2021. Salinitas tanah pada lahan yang digunakan merujuk pada pengamatan rata-rata DHL yaitu $6.66 \mathrm{ds} \mathrm{m}^{-1}$. Menurut Rachman et al. (2018), tanah tergolong salin apabila mempunyai nilai DHL lebih besar dari $4 \mathrm{ds} \mathrm{m}^{-1}$. Bahan tanaman yang digunakan adalah 22 genotipe cabai rawit (1 hibrida: Lentera F1 (G6); 5 galur murni: Batari (G2), Catas (G9), Genie (G12), Bhaskara (G18), dan Bara (G19); dan 16 galur segregant F8; G1, G3, G4, G5, G7, G8, G10, G11, G13, G14, G15, G16, G17, G20, G21, dan G22). Penelitian dilaksanakan dengan menggunakan rancangan kelompok lengkap teracak (RKLT) dengan tiga ulangan.

Pelaksanaan penelitian diawali dengan penyemaian benih selama satu bulan, penanaman, pemeliharaan hingga panen, dan pengendalian hama penyakit. Bibit dipindahkan ke lahan pada bedengan berukuran $1 \mathrm{~m}$ x $5 \mathrm{~m}$, dengan jarak antar baris dan antar tanaman $50 \mathrm{~cm}$. Jarak antar bedengan $50 \mathrm{~cm}$ dan jarak antar ulangan $100 \mathrm{~cm}$. Jumlah tanaman dalam satu bedengan sebanyak 20 tanaman dan dipilih secara acak 10 tanaman sampel pengamatan. Karakter yang diamati adalah tinggi tanaman $(\mathrm{cm})$, umur mulai berbunga (hari setelah tanam), umur mulai panen (hari setelah tanam), panjang buah $(\mathrm{mm})$, diameter buah $(\mathrm{mm})$ dan bobot buah per tanaman (g) yang merujuk pada standar UPOV (2006) untuk Capsicum annuum L. Pengamatan terhadap stomata dengan menggunakan metode kuteks pada permukaan bawah daun untuk karakter jumlah stomata (stomata per satuan bidang $320 \times 180 \mu \mathrm{m})$, panjang stomata $(\mu \mathrm{m})$, dan lebar stomata $(\mu \mathrm{m})$.

Analisis data menggunakan analisis ragam yang dilanjutkan dengan uji Duncan. Korelasi terhadap karakter bobot buah per tanaman dengan korelasi pearson menggunakan perangkat lunak SAS versi 9.4. Analisis heritabilitas arti luas ( $\left.h^{2} b s\right)$, dengan menggunakan rumus (Syukur et al. (2015) dan Riti et al. (2018) sebagai berikut:

$$
\begin{aligned}
& \mathrm{h}^{2} \mathrm{bs}=\frac{\sigma_{G}^{2}}{\sigma_{P}^{2}} \times 100 \%, \sigma^{2} \mathrm{E}=\mathrm{KTE}, \sigma_{\mathrm{G}}^{2}=\frac{K T_{G}-K T_{E}}{r} \\
& \sigma^{2} \mathrm{P}=\sigma_{G}^{2}+\sigma_{E}^{2}
\end{aligned}
$$

Keterangan:

$\mathrm{h}^{2} \mathrm{bs}=$ heritabilitas arti luas,

$\sigma_{\mathrm{G}}^{2}=$ ragam genetik,

$\sigma_{\mathrm{E}}^{2}=$ ragam lingkungan,

$\sigma_{\mathrm{P}}^{2}=$ ragam fenotipe. 
Tinggi rendahnya nilai heritabilitas digolongkan sebagai berikut: rendah $\left(\mathrm{h}^{2} \mathrm{bs} \leq 20 \%\right)$, sedang $\left(20 \%<\mathrm{h}^{2} \mathrm{bs}\right.$ $\leq 50 \%)$ dan tinggi $\left(\mathrm{h}^{2} \mathrm{bs}>50 \%\right)$.

\section{HASIL DAN PEMBAHASAN}

Pertumbuhan dan produksi suatu tanaman ditentukan oleh pengaruh genetik dan lingkungan serta interaksi antara keduanya. Hasil penelitian menunjukkan bahwa terdapat perbedaan respon pertumbuhan produksi 22 genotipe cabai rawit yang diuji pada lahan salin (Tabel 1-3). Tinggi tanaman berkisar antara $23.25 \mathrm{~cm}$ hingga 38.20 (Tabel 1). Hal ini menunjukkan bahwa tanaman yang memiliki tinggi tanaman lebih baik berpotensi menghasilkan produksi yang lebih baik. Menurut Samira et al. (2012), Zhani et al. (2012), dan Balasankar et al. (2017), genotipe cabai yang toleran salinitas memiliki kemampuan membatasi translokasi $\mathrm{Na}^{+}$ dan $\mathrm{K}^{-}$dari akar ke daun, dan mengeluarkan ion tersebut secara cepat dari daun yang dapat meningkatkan asimilasi fotosintesis dan penyesuaian osmotik untuk mempertahankan pembesaran sel yang diperlukan untuk pertumbuhan tinggi tanaman yang maksimum.
Genotipe dengan umur berbunga yang cepat, juga memperlihatkan umur panen yang cepat yaitu G5, G18, G20, dan G22 (Tabel 1). Salah satu mekanisme tanaman untuk menghindari cekaman adalah mampu mengatur plastisitas pertumbuhan tanaman dan menyelesaikan siklus hidupnya sebelum terjadi cekaman (Sujinah dan Jamil, 2016). Genotipe yang toleran salinitas berpotensi lebih cepat berbunga karena mampu mengakumulasi lebih sedikit ion garam beracun $(\mathrm{Na}$ dan $\mathrm{Cl}$ ) dalam jaringannya (Balasankar et al., 2017)

Karakter fisiologis mempengaruhi toleransi tanaman terhadap berbagai cekaman. Kerapatan stomata daun pada tanaman kedelai tidak berbeda pada tingkat salinitas tanah 1.5-15.6 dS m $\mathrm{m}^{-1}$ (Purwaningrayahu dan Taufiq, 2017). Kerapatan stomata merupakan karaktersitik suatu varietas karena lebih dipengaruhi oleh faktor genetik. Jumlah stomata dan lebar stomata tidak berpengaruh nyata terhadap peningkatan bobot buah per tanaman (Tabel 5).

Rata-rata panjang buah cabai yang diamati berkisar antara $32.37 \mathrm{~mm}$ hingga $54.33 \mathrm{~mm}$. Diameter buah dengan kisaran $6.74 \mathrm{~mm}$ sampai $8.84 \mathrm{~mm}$ (Tabel 3). Respon karakter komponen produksi terhadap cekaman salinitas

Tabel 1. Rerata nilai karakter tinggi tanaman, umur berbunga, dan umur panen pada 22 genotipe cabai rawit (Capsicum annuит L.)

\begin{tabular}{llll}
\hline Genotipe & Tinggi tanaman $(\mathrm{cm})$ & Umur berbunga (hari) & Umur panen (hari) \\
\hline G1 & $31.22 \mathrm{cdef}$ & $24.0 \mathrm{~cd}$ & $64.0 \mathrm{~cd}$ \\
G2 & $23.55 \mathrm{j}$ & $26.6 \mathrm{~b}$ & $66.6 \mathrm{~b}$ \\
G3 & $30.11 \mathrm{defgh}$ & $23.6 \mathrm{cdef}$ & $63.6 \mathrm{cde}$ \\
G4 & $27.97 \mathrm{fghi}$ & $22.1 \mathrm{hi}$ & $62.3 \mathrm{gh}$ \\
G5 & $28.17 \mathrm{efghi}$ & $23.0 \mathrm{efg}$ & $63.0 \mathrm{efg}$ \\
G6 & $31.47 \mathrm{cde}$ & $23.7 \mathrm{cde}$ & $63.7 \mathrm{cde}$ \\
G7 & $27.98 \mathrm{fghi}$ & $23.8 \mathrm{~cd}$ & $63.8 \mathrm{~cd}$ \\
G8 & $38.20 \mathrm{a}$ & $24.1 \mathrm{~cd}$ & $64.1 \mathrm{~cd}$ \\
G9 & $27.52 \mathrm{ghi}$ & $23.4 \mathrm{def}$ & $63.4 \mathrm{def}$ \\
G10 & $25.02 \mathrm{ij}$ & $21.6 \mathrm{hi}$ & $61.6 \mathrm{i}$ \\
G11 & $28.1 \mathrm{a}$ & $68.1 \mathrm{a}$ \\
G12 & $32.22 \mathrm{~cd}$ & $23.9 \mathrm{~cd}$ & $63.8 \mathrm{~cd}$ \\
G13 & $28.08 \mathrm{fghi}$ & $21.7 \mathrm{hi}$ & $61.7 \mathrm{hi}$ \\
G14 & $24.85 \mathrm{ij}$ & $23.4 \mathrm{def}$ & $63.4 \mathrm{def}$ \\
G15 & $28.20 \mathrm{efghi}$ & $21.8 \mathrm{hi}$ & $61.8 \mathrm{hi}$ \\
G16 & $30.82 \mathrm{defge}$ & $24.3 \mathrm{c}$ & $64.3 \mathrm{c}$ \\
G17 & $27.10 \mathrm{hi}$ & $21.4 \mathrm{i}$ & $61.4 \mathrm{i}$ \\
G18 & $32.19 \mathrm{~cd}$ & $22.9 \mathrm{fg}$ & $62.8 \mathrm{fg}$ \\
G19 & $27.81 \mathrm{fghi}$ & $26.6 \mathrm{~b}$ & $66.6 \mathrm{~b}$ \\
G20 & $36.55 \mathrm{ab}$ & $22.3 \mathrm{gh}$ & $62.3 \mathrm{fg}$ \\
G21 & $23.25 \mathrm{j}$ & $23.9 \mathrm{~cd}$ & $64.1 \mathrm{~cd}$ \\
G22 & $34.27 \mathrm{bc}$ & $22.3 \mathrm{gh}$ & $62.3 \mathrm{gh}$ \\
\hline
\end{tabular}

Keterangan: Angka yang diikuti huruf yang sama pada kolom yang sama berbeda tidak nyata berdasarkan DMRT pada taraf $\alpha=5 \%$ 
Tabel 2. Rerata nilai karakter jumlah stomata, panjang stomata, dan lebar stomata pada 22 genotipe cabai rawit (Capsicum annuum L.)

\begin{tabular}{lccl}
\hline Genotipe & Jumlah stomata $(\mathrm{mm})$ & Panjang stomata $(\mathrm{mm})$ & Lebar stomata $(\mathrm{mm})$ \\
\hline G1 & $2.3 \mathrm{j}$ & $30.22 \mathrm{def}$ & $17.41 \mathrm{efg}$ \\
G2 & $6.0 \mathrm{fghi}$ & $40.92 \mathrm{abc}$ & $25.01 \mathrm{abc}$ \\
G3 & $7.7 \mathrm{defg}$ & $33.88 \mathrm{cdef}$ & $18.08 \mathrm{efg}$ \\
G4 & $7.7 \mathrm{defg}$ & $31.88 \mathrm{cdef}$ & $16.58 \mathrm{fg}$ \\
G5 & $4.7 \mathrm{hij}$ & $27.78 \mathrm{f}$ & $18.19 \mathrm{efg}$ \\
G6 & $3.7 \mathrm{ij}$ & $29.43 \mathrm{ef}$ & $15.51 \mathrm{~g}$ \\
G7 & $31.95 \mathrm{cdef}$ & $18.09 \mathrm{efg}$ \\
G8 & $8.7 \mathrm{cde}$ & $38.17 \mathrm{bcde}$ & $19.59 \mathrm{cdefg}$ \\
G9 & $11.3 \mathrm{~b}$ & $48.03 \mathrm{a}$ & $26.78 \mathrm{ab}$ \\
G10 & $4.0 \mathrm{ij}$ & $41.51 \mathrm{abc}$ & $21.76 \mathrm{bcdef}$ \\
G11 & $37.24 \mathrm{bcdef}$ & $23.24 \mathrm{abcde}$ \\
G12 & $3.0 \mathrm{ij}$ & $38.63 \mathrm{abcde}$ & $16.78 \mathrm{fg}$ \\
G13 & $8.3 \mathrm{cdef}$ & $33.96 \mathrm{cdef}$ & $20.49 \mathrm{cdefg}$ \\
G14 & $2.7 \mathrm{j}$ & $33.47 \mathrm{cdef}$ & $18.98 \mathrm{defg}$ \\
G15 & $10.3 \mathrm{bc}$ & $34.16 \mathrm{cdef}$ & $20.28 \mathrm{cdefg}$ \\
G16 & $5.7 \mathrm{ghi}$ & $33.75 \mathrm{cdef}$ & $21.38 \mathrm{bcdefg}$ \\
G17 & $4.0 \mathrm{ij}$ & $39.93 \mathrm{abcd}$ & $21.62 \mathrm{bcdef}$ \\
G18 & $2.3 \mathrm{j}$ & $29.12 \mathrm{ef}$ & $20.07 \mathrm{cdefg}$ \\
G19 & $8.0 \mathrm{cdefg}$ & $34.82 \mathrm{cdef}$ & $27.93 \mathrm{a}$ \\
G20 & $6.7 \mathrm{efgh}$ & $33.40 \mathrm{cdef}$ & $22.49 \mathrm{abcdef}$ \\
G21 & $9.3 \mathrm{bcd}$ & $29.12 \mathrm{ef}$ & $23.37 \mathrm{abcd}$ \\
G22 & $2.3 \mathrm{j}$ & $45.33 \mathrm{ab}$ & $24.66 \mathrm{abcd}$ \\
\hline
\end{tabular}

Keterangan: Angka yang diikuti huruf yang sama pada kolom yang sama berbeda tidak nyata berdasarkan DMRT pada taraf $\alpha=5 \%$

berbeda antar genotipe yang diamati. Karakteristik cabai rawit yang disukai oleh konsumen adalah tingkat kepedasan yang tinggi, warna buah merah dan ukuran buah besar yaitu buah yang panjang dan diameter buah yang besar. Ratarata karakter komponen produksi terbaik untuk panjang buah adalah $\mathrm{G} 17$, diameter buah adalah G3, G17, G1, dan G20, sedangkan untuk bobot buah per tanaman adalah G17. Panjang buah berkorelasi nyata terhadap peningkatan bobot buah per tanaman, sedangkan diameter buah tidak menunjukkan korelasi nyata terhadap peningkatan bobot buah per tanaman (Tabel 4). Salinitas sangat berpengaruh terhadap penurunan produksi cabai merah (Huez-Lopez et al., 2011; Jamil et al., 2018) yang disebabkan oleh gangguan keseimbangan hormon dan penyerapan air yang semakin berkurang terhadap tingkat salinitas yang semakin tinggi. Hal sama juga dilaporkan terjadi pada tomat (Kahlaoui et al., 2013).

Genotipe cabai rawit toleran dapat direkomendasikan untuk dikembangkan di lahan salin yang didasarkan pada kemampuan genotipe tersebut tetap berproduksi dengan baik dibandingkan dengan genotipe lainnya meskipun mengalami cekaman salinitas. Karakter produksi sangat kompleks dan dipengaruhi oleh banyak faktor. Informasi karakter yang memiliki korelasi erat dengan komponen produksi (bobot buah per tanaman) sangat membantu proses seleksi yang dilakukan. Karakter yang memiliki keterkaitan erat terhadap peningkatan bobot buah per tanaman adalah tinggi tanaman, umur berbunga dan umur panen, serta panjang buah (Tabel 4 ). Umur panen sejalan dengan umur berbunga dan memperlihatkan korelasi yang sangat nyata terhadap bobot buah per tanaman. Jumlah stomata dan lebar stomata tidak berpengaruh nyata terhadap peningkatan bobot buah per tanaman.

Karakter yang berkorelasi terhadap bobot buah per tanaman juga memiliki nilai heritabilitas dengan kriteria tinggi (Tabel 5). Heritabilitas yang tinggi menunjukkan bahwa karakter tersebut lebih dominan dikendalikan oleh faktor genetik dibandingkan faktor lingkungan. Pada lingkungan optimal, tanaman cabai rawit dilaporkan memiliki nilai heritabilitas arti luas kategori tinggi pada karakter untuk umur berbunga (Lestari et al., 2006; Singh et al., 2014), umur panen (Arif et al., 2012), fruit length and diameter (Syukur dan Rosidah, 2014), tinggi tanaman (Nsabiera et al., 2013), panjang buah, dan diameter buah (Santos et al., 2014). 
Tabel 3. Rerata nilai karakter panjang buah, diameter buah, dan bobot buah pada 22 genotipe cabai rawit (Capsicum annuum L.)

\begin{tabular}{|c|c|c|c|}
\hline Genotipe & Panjang buah (mm) & Diameter buah (mm) & Bobot buah per tanaman $(\mathrm{g})$ \\
\hline G1 & $45.79 \mathrm{~b}$ & $8.59 \mathrm{ab}$ & $440.13 \mathrm{kl}$ \\
\hline $\mathrm{G} 2$ & $32.37 \mathrm{~h}$ & 7.64def & $481.92 \mathrm{kl}$ \\
\hline G3 & $44.72 b$ & $8.84 a$ & $569.11 \mathrm{ijk}$ \\
\hline G4 & $40.30 \mathrm{~cd}$ & $8.18 \mathrm{bcd}$ & $775.38 \mathrm{fgh}$ \\
\hline G5 & $34.55 \mathrm{fgh}$ & $7.48 \mathrm{efg}$ & $557.90 \mathrm{ijk}$ \\
\hline G6 & $38.67 \mathrm{cde}$ & $7.43 \mathrm{efg}$ & $1,066.46 \mathrm{bc}$ \\
\hline G7 & $47.01 \mathrm{~b}$ & $7.01 \mathrm{gh}$ & $513.09 \mathrm{ijk}$ \\
\hline G8 & $34.28 \mathrm{gh}$ & $7.89 \mathrm{de}$ & $688.63 \mathrm{ghi}$ \\
\hline G9 & $36.23 \mathrm{efg}$ & $7.63 \mathrm{def}$ & 667.34ghi \\
\hline G10 & $40.29 \mathrm{~cd}$ & $7.48 \mathrm{efg}$ & 866.94def \\
\hline G11 & $37.27 \mathrm{defg}$ & 7.70def & $252.56 \mathrm{~m}$ \\
\hline G12 & $39.78 \mathrm{cde}$ & $7.18 \mathrm{fgh}$ & 651.03hij \\
\hline G13 & $37.89 \mathrm{cdef}$ & $7.14 \mathrm{fgh}$ & $680.32 \mathrm{ghi}$ \\
\hline G14 & $37.51 \mathrm{cdefg}$ & $7.51 \mathrm{efg}$ & $333.381 \mathrm{~m}$ \\
\hline G15 & $44.68 b$ & $7.62 \mathrm{def}$ & $1,159.18 b$ \\
\hline G16 & $40.34 \mathrm{~cd}$ & $8.00 \mathrm{cde}$ & 644.44hij \\
\hline G17 & $54.33 \mathrm{a}$ & $8.67 \mathrm{ab}$ & $1,430.42 \mathrm{a}$ \\
\hline G18 & $41.10 \mathrm{c}$ & 7.70def & $998.24 \mathrm{bcd}$ \\
\hline G19 & $38.20 \mathrm{cde}$ & 7.69def & $1,042.14 b c$ \\
\hline G20 & $45.82 b$ & $8.43 \mathrm{abc}$ & $826.16 \mathrm{efg}$ \\
\hline G21 & 39.49 cde & $6.74 \mathrm{~h}$ & $1,111.38 b c$ \\
\hline G22 & $34.01 \mathrm{gh}$ & $6.98 \mathrm{gh}$ & $945.32 \mathrm{cde}$ \\
\hline
\end{tabular}

Keterangan: Angka yang diikuti huruf yang sama pada kolom yang sama berbeda tidak nyata berdasarkan DMRT pada taraf $\alpha=5 \%$

Tabel 4. Korelasi fenotipe karakter pada 22 genotipe cabai rawit (Capsicum annuum L.)

\begin{tabular}{|c|c|c|c|c|c|c|c|c|}
\hline & TT & UB & UP & JS & LS & $\mathrm{PB}$ & DB & $\mathrm{BB}$ \\
\hline TT & 1 & $0.17 \mathrm{tn}$ & $0.17 \mathrm{tn}$ & $0.46^{* *}$ & $0.06 \mathrm{tn}$ & $-0.03 \mathrm{tn}$ & $0.04 \mathrm{tn}$ & $0.32 *$ \\
\hline UB & & 1 & $0.99 * *$ & $0.14 \mathrm{tn}$ & $0.19 \mathrm{tn}$ & $-0.32 * *$ & $-0.02 \mathrm{tn}$ & $-0.44 * *$ \\
\hline UP & & & 1 & $0.16 \mathrm{th}$ & $0.19 \mathrm{tn}$ & $-0.33 * *$ & $-0.03 \operatorname{tn}$ & $-0.43 * *$ \\
\hline JS & & & & 1 & $0.27 *$ & $-0.14 \mathrm{tn}$ & $-0.29 *$ & $0.18 \mathrm{tn}$ \\
\hline LS & & & & & 1 & $-0.21 \mathrm{tn}$ & $-0.18 \mathrm{tn}$ & $0.11 \mathrm{tn}$ \\
\hline PB & & & & & & 1 & $0.47 * *$ & $0.35 * *$ \\
\hline DB & & & & & & & 1 & $-0.02 \mathrm{tn}$ \\
\hline $\mathrm{BB}$ & & & & & & & & 1 \\
\hline
\end{tabular}

Keterangan: $\mathrm{TT}=$ tinggi tanaman; $\mathrm{UB}=$ umur berbunga; $\mathrm{UP}=$ Umur panen; JS = jumlah stomata; $\mathrm{LS}=$ lebar stomata; $\mathrm{PB}=$ panjang buah; $\mathrm{DB}=$ diameter buah; $\mathrm{BB}=$ Bobot buah per tanaman 
Tabel 5. Ragam lingkungan, ragam genetik, ragam fenotipe dan heritabilitas pada karakter yang diamati

\begin{tabular}{lrrrrrr}
\hline Karakter & $\begin{array}{c}\text { Kuadrat tengah } \\
\text { genotipe }\end{array}$ & $\begin{array}{c}\text { Kuadarat } \\
\text { tengah galat }\end{array}$ & $\begin{array}{c}\text { Ragam } \\
\text { genetik }\end{array}$ & $\begin{array}{c}\text { Ragam } \\
\text { fenotipe }\end{array}$ & $\begin{array}{c}\text { Heritabilitas } \\
\text { arti luas }\end{array}$ & Kriteria \\
\hline Tinggi tanaman & 45.29 & 3.18 & 14.04 & 17.22 & $81.53 \%$ & Tinggi \\
Umur berbunga & 8.87 & 0.16 & 2.90 & 3.07 & $94.75 \%$ & Tinggi \\
Umur panen & 8.85 & 0.15 & 2.90 & 3.05 & $95.05 \%$ & Tinggi \\
Jumlah stomata & 33.48 & 1.95 & 10.51 & 12.46 & $84.34 \%$ & Tinggi \\
Panjang stomata & 86.76 & 27.21 & 19.85 & 47.06 & $42.18 \%$ & Sedang \\
Lebar stomata & 33.89 & 9.10 & 8.26 & 17.36 & $47.59 \%$ & Sedang \\
Panjang buah & 80.08 & 3.66 & 25.48 & 29.13 & $87.45 \%$ & Tinggi \\
Diameter buah & 0.95 & 0.09 & 0.29 & 0.37 & $77.19 \%$ & Tinggi \\
Bobot buah & $259,369.24$ & $8,714.67$ & $83,551.52$ & $92,266.19$ & $90.55 \%$ & Tinggi \\
\hline
\end{tabular}

\section{KESIMPULAN}

Pertumbuhan dan produksi cabai rawit yang ditanam pada lahan salin menunjukkan respon yang berbeda antar genotipe. karakter yang menjadi kriteria seleksi toleran salinitas adalah tinggi tanaman, umur berbunga, umur panen dan panjang buah karena memiliki pengaruh yang nyata terhadap bobot buah per tanaman dan kriteria nilai heritabilitas tinggi. Berdasarkan karakter tersebut genotipe terpilih sebagai calon varietas toleran adalah G17. Genotipe ini dapat direkomendasikan untuk pengembangan cabai rawit di lahan salin.

\section{UCAPAN TERIMA KASIH}

Ucapan terima kasih disampaikan kepada Kemenristek/ BRIN dan LPDP yang telah membiayai penelitian ini melalui skema PRN tahun 2020 a.n. Marlina Mustafa dengan kontrak nomor 34/E1/PRN/2020.

\section{DAFTAR PUSTAKA}

Arif, A.B., S.Sujiprihati, M. Syukur. 2012. Estimation of several genetic parameter on quantitative characters of hybridization between big and curly chili (Capsicum annuum L.). J. Agron. Indonesia 40:119-124.

Balasankar, D., S. Praneetha, T. Arumugam, N. Manivanna, P. Jeyakumar, K. Arulmozzhiselvan. 2017. Assessment pf salinity tolerance in chili (capsicum annuum L.) genotypes. Int. J. Chem. Stud. 5:1194-1198.

Huez-Lopez, M.A., A.L. Ulery, Z. Samani, G. Picchioni and R.P. Flynn. 2011. Response of chile pepper (Capsicum anuum L.) to salt stress and organic and inorganic nitrogen sources: Nitrogen and water use efficiencies, and salt tolerance. Trop. Subtrop. Agroecosystems 14:757-763.
Ifediora, N.H., H.O. Edeoga, G. Omosun. 2014. Effects of salinity on the growth and visocosity of fruits of Okra (Abelmoschus esculentus L.). Int. J. Curr. Agric. Res. 1:081-084.

Jamil, M., M.A. Kharal, M. Ahmad, G.H. Abbasi, F. Nazli, A. Hussain, M.F. Akhtar. 2018. Inducing salinity tolerance in red pepper (Capsicum annuum L.) through exogenous application of proline and Ltryptophan. Soil Environ. 37:11-19.

Kahlaoui, B., M. Hachicha, J. Teixeira, E. Misle, F. Fidalgo, B. Hanchi. 2013. Response of two tomato cultivars to field-applied proline and salt stress. J. Stress Physiol. Biochem. 9:357-365.

Lestari, A.D., W. Dewi, W.A. Qosim, M. Rahardja, N. Rostini, R. Setiamihardja. 2006. Genetic variability and heritability of yield components and yield characters of fteen red pepper genotypes. Zuriat 17 : 94-102.

Fauzia, M. 2021. Pedasnya cabai rawit jadi penyumbang inflasi Maret 2021. https://money.kompas.com [12 Juni 2021].

Narwiyan, Rosmayati, E. Bayu. 2016. Sebaran normal karakter pertumbuhan dan produksi hasil persilangan kedelai (Glycine max L. Merril) varietas anjasmoro dengan genotipa kedelai tahan salin pada F2. J. Agroekoteknologi 4:2300-2307.

Niu, G., D.S. Rodriguez, E. Call, P.W.A Bosland, A. Ulery, E. Acosta. 2010. Responses of eight chile peppers to saline water irrigation. Sci. Hort. 126:215-222.

Nizam, U.A., U.M. Nashir, A.U.Zaman, F. Zannatul, C.H. Shyam. 2017. Effect of different salinity level on tomato production under climate change condition in Bangladesh. Annu. Res. Rev. Biol. 13:1-9. 
Nsabiera, V., M. Ohwo-Ssemakula, M.P. Seruwagi, C. Ojiewo, P. Gipson. 2013. Combining ability for field resistance to disease, fruit field and field factors among hot pepper (Capsicum annuum L.) genotypes in Uganda. Int. J. Plant Breeding 7:12-21.

Purwaningrahayu, R.D., A. Taufiq. 2017. Respon morfologi empat genotipe kedelai terhadap cekaman salinitas. J. Biologi Indonesia 13:175-188.

[Pusdatin] Pusat Data dan Sistem Informasi Pertanian. 2020. Outlook Cabai. http://epublikasi.pertanian.go.id [14 April 2021].

Qadir, M. 2016. Reversing salt-induced land degradation requires integrated measures. Water Econ. Policy $2: 1-8$

Rachman, A., A. Dariah, S. Sutono. 2018. Pengelolaan Sawah Salin Berkadar Garam Tinggi. IAARD Press, Jakarta, Indonesia.

Samira, I.M., B. Dridi-Mouhande, S. Mansour-Gueddes, Denden. 2012. 24-epibrassinolide ameliorates the adverse effect of salt stress $(\mathrm{NaCl})$ on pepper (Capsicum annuum L.). J. Stress Physiol. Biochem. 8:232-240.

Santos, R.M.C., E.R. doRêgo, A. Borém, M.F. Nascimento, N.F.F. Nascimento, F.L. Finger, M.M. Rêgo. 2014. Epistasis and inheritance of plant habit and fruit quality traits in ornamental pepper (Capsicum annuиm L.). Genet. Mol. Res. 13:8876-8887.
Singh, P., D.S. Cheema, M.S. Dhaliwal, N. Garg. 2014. Heterosis and combining ability for earliness, plant growth, yield and fruit attributes in hot pepper (Capsicum annuum L.) involving genetic and cytoplasmic-genetic male sterile lines. Sci. Hort. 168:175-188.

Sujinah, A. Jamil. 2016. Mekanisme respon tanaman padi terhadap cekaman kekeringan dan varietas toleran. Iptek Tanaman Pangan 11:1-8.

Sukarman, A, Mulyani, S. Purwanto. 2018. Modifikasi metode evaluasi kesesuaian lahan berorientasi perubahan iklim. J. Sumberdaya Lahan 12:1-11.

Syukur, M., S. Rosidah. 2014. Estimation of genetic parameter for quantitative characters of pepper (Capsicun annuum L.). J. Tropical Crops 1:4-8.

Yunandra, M. Syukur, A. Maharijaya. 2017. Seleksi dan kemajuan karakter komponen hasil pada persilangan cabai keriting dan cabai besar. J. Agron. Indonesia 45:169-174.

Yuniarta, L., K. Hidayat. 2021. Kementan targetkan produksi cabai meningkat 7\% tahun ini. https://www.nasional. kontan.co.id/ [25 April 2021].

Zhani, K., M.A. Elouer, H. Aloui, C. Hannachi. 2012. Selection of a salt tolerant Tunisian cultivar of chilli (Capsicum frutescens). Eurasia J. Biosci. 6:47-59. 